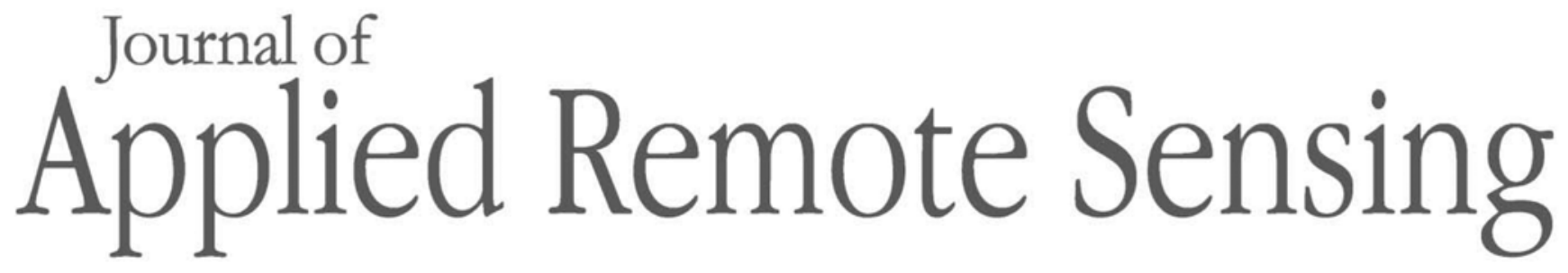

RemoteSensing.SPIEDigitalLibrary.org

\title{
Sensitivity analyses of precipitable water vapor retrieval from the ground-based infrared measurements in clear sky conditions
}

Qi Zhou

Hailei Liu

Shenglan Zhang

Xiaobo Deng 


\title{
Sensitivity analyses of precipitable water vapor retrieval from the ground-based infrared measurements in clear sky conditions
}

\author{
Qi Zhou, ${ }^{a}$ Hailei Liu, ${ }^{\text {a,b,* }}$ Shenglan Zhang, ${ }^{a}$ and Xiaobo Deng ${ }^{a}$ \\ ${ }^{a}$ Chengdu University of Information Technology, Key Laboratory of Atmospheric Sounding, \\ Chengdu, China \\ ${ }^{\mathrm{b} C h i n a}$ Meteorological Administration, National Satellite Meteorology Center, \\ Beijing, China
}

\begin{abstract}
Feasibility of precipitable water vapor (PWV) retrieval from the ground-based infrared measurements in clear sky conditions was performed based on the radiative transfer simulation and retrieval experiments. The effects of aerosol, view zenith angle, and instrument spectral response function (SRF) on clear-sky infrared brightness temperature $\left(T_{\text {sky }}\right)$ were analyzed. The results showed that atmospheric aerosol and SRF have obvious influence on $T_{\text {sky }}$ measurements and PWV retrievals. The relationship between $T_{\text {sky }}$ and PWV under low aerosol loading conditions is better than that of high aerosol loading conditions. Aerosol information is necessary for the inversion of high-precision PWV using a single-angle $T_{\text {sky }}$ measurement. $T_{\text {sky }}$ at the infrared atmospheric window (i.e., 10 to $12 \mu \mathrm{m}$ ) has a better exponential relationship with PWV than that covers $6.3 \mu \mathrm{m}$ water vapor and $9.6 \mu \mathrm{m}$ ozone absorption bands. Furthermore, a neural network (NN)-based PWV retrieval algorithm was proposed using dual-angle $T_{\text {sky }}$ measurements and near-surface air temperature $\left(T_{\text {air }}\right)$. The results showed that the introduction of multiangle $T_{\text {sky }}$ can effectively reduce the influence of aerosol on PWV retrieval and improve the PWV retrieval accuracy. The determination coefficient, root-mean-square error, and bias of the NN model using dual-angle $T_{\text {sky }}$ (i.e., 0 deg and $30 \mathrm{deg}$ ) and $T_{\text {air }}$ were $0.989,0.191$, and $0.002 \mathrm{~cm}$, respectively. (1) The Authors. Published by SPIE under a Creative Commons Attribution 4.0 Unported License. Distribution or reproduction of this work in whole or in part requires full attribution of the original publication, including its DOI. [DOI: 10.1117/1.JRS.13.044513]
\end{abstract}

Keywords: precipitable water vapor retrieval; infrared radiometer; sky brightness temperature; MODTRAN; aerosol.

Paper 190415 received Jun. 6, 2019; accepted for publication Oct. 14, 2019; published online Oct. 31, 2019.

\section{Introduction}

Water vapor in the atmosphere and its changes are the main drivers of weather and climate change. ${ }^{1,2}$ It has important applications in precipitation and severe weather forecasting, atmospheric radiation research, water cycle, and global climate change research., ${ }^{2,3}$ Precipitable water vapor (PWV) is the total atmospheric water vapor contained in a vertical column of unit cross-sectional area extending from the Earth's surface to the top of the atmosphere. PWV is an essential parameter for climate energy budgets, hydrological cycles, and numerical weather prediction. ${ }^{3,4}$ Moreover, PWV is one of the main geophysical parameters that affect land surface remote sensing, such as land surface temperature and surface reflectance retrievals. ${ }^{5-7}$

A number of techniques have been used to obtain the PWV such as radiosonde, GPS, microwave radiometer, ground-based sun photometer, and satellite remote sensing. ${ }^{8-10}$ Radiosonde can provide high precision water vapor products, but it is usually released twice per day and its typical spatial resolution is about 200 to $300 \mathrm{~km} .{ }^{11,12}$ Satellite remote sensing can provide PWV information at larger scales, but its accuracy and temporal resolution are usually lower than the ground-based remote sensing techniques. ${ }^{13,14}$

*Address all correspondence to Hailei Liu, E-mail: liuhailei@ cuit.edu.cn 
Ground-based remote sensing techniques such as microwave radiometer, GPS, sun photometer, and laser radar can measure PWV with high accuracy and high temporal resolution. . $^{1,9} 15-17$ However, the ground-based remote sensing equipment is generally expensive and not convenient to carry. In contrast, infrared thermometers and infrared radiometers have the advantages of small volume and low cost, and are convenient to carry, which provides a possible way for low-cost PWV sounding. ${ }^{18,19}$

At present, a number of studies have been carried out to estimate PWV using ground-based infrared observations. Maghrabi and Clay used the clear sky temperature obtained by an IR radiometer observation and air temperature to estimate PWV. The detector was a thermopile with a spectral response from 6.6 to $20 \mu \mathrm{m}$. They compared the measurements of the cloud-free zenith sky with GPS PWV. The RMSE of the estimated PWV was about $2.3 \mathrm{~mm} .{ }^{18}$ Mims proposed a simple method for PWV estimation from the zenith clear sky brightness temperature ( $\left.T_{\text {sky }}\right)$ by a handheld infrared thermometer. ${ }^{19}$ Their results showed that the $T_{\text {sky }}$ is related to the GPS PWV. The exponential function was used to convert $T_{\text {sky }}$ to PWV, the RMSE of PWV estimation is $\sim 4.0 \mathrm{~mm}$.

However, the existing research is mainly to perform PWV estimation based on the actual observation data of specific instruments with fixed SRF. The influences of SRF, aerosol, and view zenith angle (VZA) on $T_{\text {sky }}$ and PWV retrieval need further analysis. In this study, the feasibility of PWV retrieval for several SRFs under different atmospheric aerosol models were analyzed based on the radiative transfer simulations and retrieval experiments.

\section{Theoretical Basis}

The downwelling atmospheric radiance observed by a ground-based infrared radiometer at the cloud-free zenith sky can be expressed as $^{20}$

$$
I_{\lambda}=B_{\lambda}\left(\mathrm{T}_{\text {sky }}\right)=\int_{0}^{p_{s}} B_{\lambda}[T(p)] \frac{\partial T_{\lambda}(p)}{\partial p} \mathrm{dp},
$$

where $B$ is the Planck function, $\lambda$ is the wavelength, $T_{\text {sky }}$ is the clear-sky infrared brightness temperature, $p_{s}$ is the surface pressure, $T(p)$ is the atmospheric temperature at pressure level $p$, and $T_{\lambda}(p)$ represents the total transmittance of the atmosphere between the pressure $p$ and surface. Furthermore, Eq. (1) can also be written as

$$
I_{\lambda}=B_{\lambda}\left(\mathrm{T}_{\text {sky }}\right)=\int_{0}^{p_{s}} B_{\lambda}[T(p)] W(p) \mathrm{dp},
$$

where $W(p)=\partial T_{\lambda}(p) / \partial p$ is the weighting function. Equation (1) is fundamental for remote sensing of the atmosphere from ground-based infrared sensors. The downwelling radiance is the product of Planck function and the weighting function. The air temperature information is included in the Planck function, and the density profiles of relevant absorbing gases (i.e., $\mathrm{H}_{2} \mathrm{O}, \mathrm{O}_{3}, \mathrm{CO}_{2}, \mathrm{CH}_{4}$, and $\mathrm{N}_{2} \mathrm{O}$ ) are involved in the transmittance. ${ }^{20}$ Therefore, the observed radiance will thus be directly or indirectly associated with the temperature and gaseous profiles.

Figure 1 shows the transmittances of the major absorbing gases (i.e., $\mathrm{H}_{2} \mathrm{O}, \mathrm{O}_{3}, \mathrm{CO}_{2}, \mathrm{CH}_{4}$, and $\mathrm{N}_{2} \mathrm{O}$ ) in 5.0 to $14.5 \mu \mathrm{m}$ for the standard mid-latitude summer (MLS) atmosphere. Water vapor exhibits absorption lines almost over the entire infrared spectrum, and the most pronounced absorption occurs in the $6.3-\mu \mathrm{m}$ vibrational-rotational band. From about 8.3 to $12.5 \mu \mathrm{m}$, referred to as the atmospheric window, absorption due to atmospheric gases shows a minimum except the $9.6-\mu \mathrm{m}$ ozone band. ${ }^{20}$

There are also absorption bands for various greenhouse gases (i.e., the $\mathrm{CH}_{4} 7.6 \mu \mathrm{m}$ band, the $\mathrm{N}_{2} \mathrm{O} 7.9 \mu \mathrm{m}$ band) that can be used for their determination by remote sensing. The transmittance and weighting function are quite different over different spectral range, $T_{\text {sky }}$ is mainly related to atmospheric temperature and humidity profile over the spectral range in which water vapor is the dominant absorbing gas. Furthermore, it is worth mentioning that aerosols also have influence on 


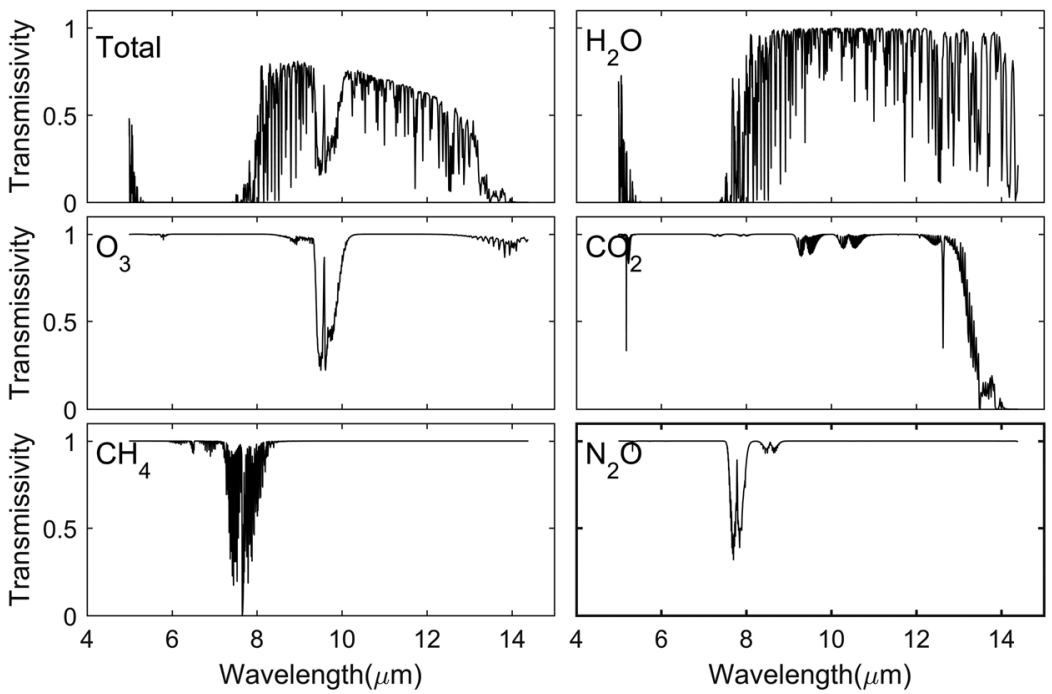

Fig. 1 Atmospheric transmittances of various absorbing gases calculated by the MODTRAN 5.2 for the standard MLS atmosphere in 5.0 to $14.5 \mu \mathrm{m}$.

the infrared radiative transfer processes in addition to the absorption of gases. ${ }^{20}$ Therefore, it is necessary to analyze the influence of wavelength and aerosol on PWV retrieval.

\section{Dataset and Radiation Transfer Simulation}

\subsection{Dataset and Study Area}

In this study, $T_{\text {sky }}$ was simulated using the clear sky global training database (SeeBor V5.0 ${ }^{21}$ ) and MODTRAN (Moderate Resolution Atmospheric Transmittance Model, version 5.2). The training database consists of 15,704 profiles of temperature, moisture, and ozone at 101 pressure levels for clear sky conditions worldwide.

The study area was located over $30^{\circ}$ to $40^{\circ} \mathrm{N}, 100^{\circ}$ to $120^{\circ} \mathrm{E}$. There were 198 profiles in the area (Fig. 2). The selected profiles can represent a variety of atmospheric conditions, with the elevation of these profiles ranges from 0 to $4572 \mathrm{~m}$ and the PWV ranges from 0.18 to $6.41 \mathrm{~cm}$.

\section{2 $\mathrm{T}_{\text {sky }}$ Simulation}

As mentioned above, $T_{\text {sky }}$ over different bands may be quite different. Therefore, it is necessary to analyze the influence of spectral characteristics of the radiometer on the $T_{\text {sky }}$ measurements and the accuracy of PWV retrieval. In this study, three SRFs (Fig. 3) within 5.0 to $14.5 \mu \mathrm{m}$ were

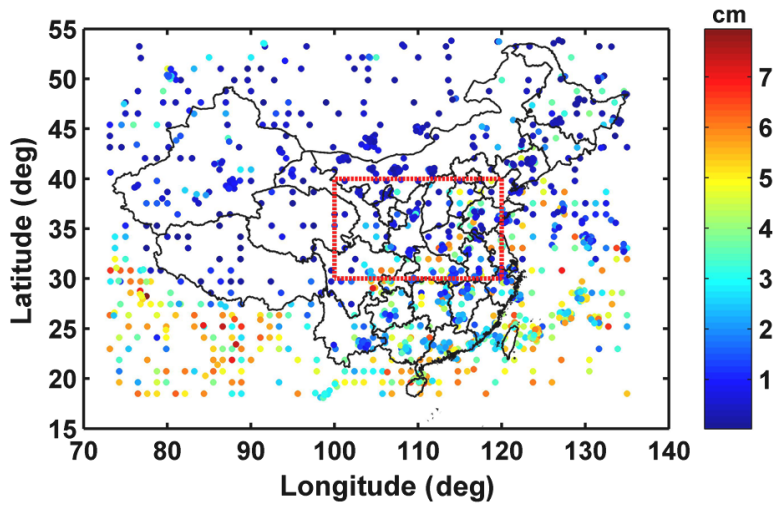

Fig. 2 Geographical location and PWV of the atmospheric profiles (within the rectangular box) used in this study. 


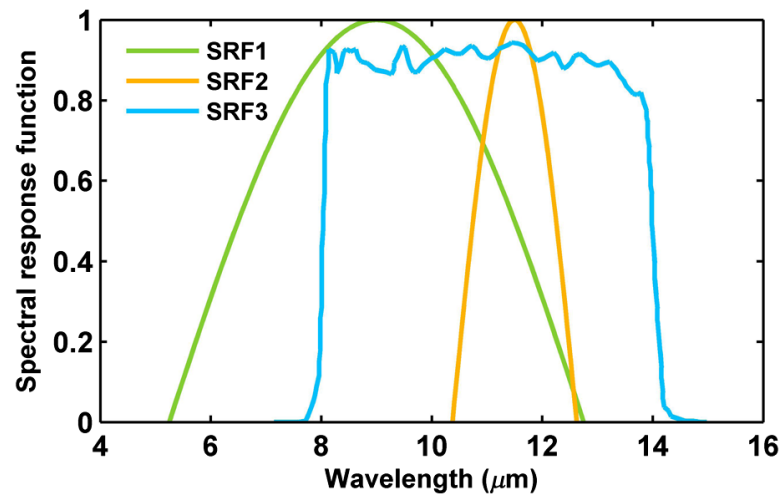

Fig. 3 The three SRFs used in this study.

Table 1 Characteristics of the three SRFs used in this study.

\begin{tabular}{lcc}
\hline \hline SRFs & Central wavelength $(\mu \mathrm{m})$ & FWHM $(\mu \mathrm{m})$ \\
\hline SRF1 & 9.0 & 5.0 \\
SRF2 & 11.5 & 1.5 \\
SRF3 (apogee) & 11.0 & 5.0 \\
\hline \hline
\end{tabular}

used. SRFs 1 and 2 were generated by cosine function with different central wavelength and full width at half maximum (FWHM) (Table 1), and SRF3 was the actual spectral response of apogee SI series infrared radiometer. ${ }^{22}$

Two MODTRAN built-in aerosol models (i.e., rural and urban types) were used in the radiative transfer simulations in the boundary layer ( 0 to $2 \mathrm{~km}$ altitude) ${ }^{23}$ The aerosol above $2 \mathrm{~km}$ were set to MODTRAN's default settings ( 2 to $10 \mathrm{~km}$ : tropospheric aerosol, $>10 \mathrm{~km}$ : stratospheric aerosol). The aerosol models in MODTRAN mainly come from LOWTRAN aerosol climatology. The LOWTRAN aerosol data contain the aerosol profiles, single scattering albedos (SSA), asymmetry parameters (ASY), and extinction coefficients (EXT) at 47 wavelengths from 0.2 to $300 \mu \mathrm{m}$ for several aerosol types (e.g., rural and urban type aerosols). ${ }^{24,25}$

Rural aerosol is assumed to be composed of $70 \%$ water soluble material (ammonium, calcium sulfate, and organic compounds) and 30\% dust-like aerosol. ${ }^{24}$ The urban aerosol is taken to be a mixture of the rural aerosol $(80 \%)$ with soot-like carbonaceous aerosol (20\%). SSA, ASY, and EXT vary with relative humidity (RH) and the aerosol profiles depend on visibility (VIS) ${ }^{26}$ The attenuation coefficients of urban and rural aerosol at $70 \% \mathrm{RH}$ with VIS $=5 \mathrm{~km}$ were presented in Fig. 4.

MODTRAN uses VIS to characterize the aerosols loading. The VIS specifies the surface meteorological range $(\mathrm{km})$ overriding the boundary layer aerosol:

$$
\operatorname{VIS~}(\mathrm{km})=\frac{\ln (50)}{\operatorname{EXT550}\left(\mathrm{km}^{-1}\right)+0.01159 \mathrm{~km}^{-1}},
$$

where $0.01159 \mathrm{~km}^{-1}$ is the surface Rayleigh scattering coefficient at $550 \mathrm{~nm}$. EXT550 $\left(\mathrm{km}^{-1}\right)$ is the surface aerosol extinction at $550 \mathrm{~nm}$.

Two aerosol types (i.e., rural and urban models) were selected and VIS were set to 1, 2, 3, 4, and $5 \mathrm{~km}$, respectively. The VZAs were set to $0 \mathrm{deg}$ and $30 \mathrm{deg}$ for each atmospheric profile. Finally, a total number of 11,880 radiative transfer calculations (198 profiles $\times 3$ SRFs $\times$ 2 VZAs $\times 5$ VISs $\times 2$ aerosol types) were performed using MODTRAN 5.2. The Gaussiandistributed random noise was added to get better simulations of real $T_{\text {sky }}$ data. For simplicity, the standard deviations of the noise equivalent delta temperature (NE $\Delta \mathrm{T}$ ) for SRFs 1 to 3 were set at $0.3 \mathrm{~K}$ according to the design requirement for apogee SI series infrared radiometer. In addition, the $T_{\text {sky }}$ were also calculated for the MLS and mid-latitude winter (MLW) standard atmosphere for different VZAs, VIS, and aerosol types. 

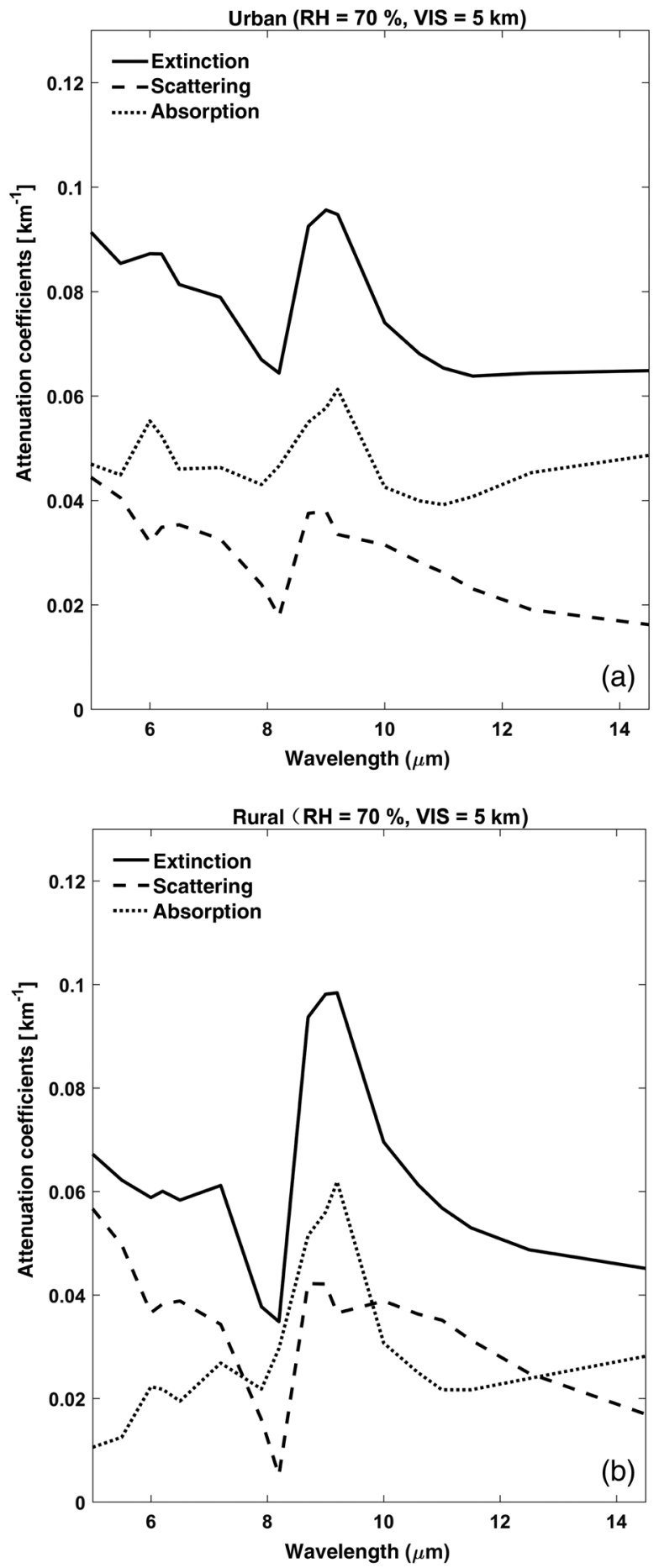

Fig. 4 Attenuation coefficients for (a) urban and (b) rural aerosol at 70\% $\mathrm{RH}$.

\subsection{PWV Retrieval Algorithm by Neural Network Model}

Artificial neural networks (NN) are computing systems based on a collection of connected artificial neurons and are especially suited for handling nonlinear and complex problems. ${ }^{27,28}$ $\mathrm{NN}$ techniques can describe the relationship between inputs and outputs from training data and have been widely used in geophysical parameter estimations.

In this study, a multilayer feed-forward NN was used to retrieve PWV using the $T_{\text {sky }}$ and other auxiliary data. Half of the simulated data were used to train the NN, and the other half were used to validate the trained $\mathrm{NN}$. 
Three statistical factors, determination coefficient $\left(R^{2}\right)$, root-mean-square error (RMSE), and bias were used to evaluate the accuracy of PWV estimation models as follows:

$$
\begin{gathered}
R^{2}=\frac{\sum\left(\mathrm{PWV}_{\text {ret }}-\overline{\mathrm{PWV}_{\text {ret }}}\right)\left(\mathrm{PWV}_{\text {true }}-\overline{\mathrm{PWV}_{\text {true }}}\right)}{\left.\sqrt{\left.\sum\left(\mathrm{PWV}_{\text {ret }}-\overline{\mathrm{PWV}}\right)_{\text {ret }}\right)^{2} \sum\left(\mathrm{PWV}_{\text {true }}-\overline{\mathrm{PWV}}\right)_{\text {true }}}\right)^{2}}, \\
\mathrm{RMSE}=\sqrt{\frac{\sum_{i=1}^{N}\left(\mathrm{PWV}_{\text {ret }}-\mathrm{PWV}_{\text {true }}\right)^{2}}{N}}, \\
\text { bias }=\frac{\sum_{i=1}^{N}\left(\mathrm{PWV}_{\text {ret }}-\mathrm{PWV}_{\text {true }}\right)}{N},
\end{gathered}
$$

where $\mathrm{PWV}_{\text {ret }}$ is the retrieved PWV, PWV true is the true PWV of the global training profiles dataset, and $N$ is the sample size. In general, $R^{2}$ is used to assess the degree of consistency but not absolute agreement, and a positive (negative) bias indicates an overestimation (underestimation) of PWV. Low RMSE values indicate a small discrepancy between the estimated and the true PWV.

\section{Results and Discussion}

\subsection{Relationship Between $\mathrm{T}_{\text {sky }}$ and PWV}

Figure 5 showed the $T_{\text {sky }}$ spectrum in 5.0 to $14.5 \mu \mathrm{m}$ of the MLS and MLW standard atmosphere. The $T_{\text {sky }}$ in summer is generally higher than that in winter due to the higher air temperature and water vapor in summer. The $T_{\text {sky }}$ spectrum of MLS atmosphere mainly ranges from 220 to $294 \mathrm{~K}$ and MLW atmosphere ranges from 168 to $272 \mathrm{~K}$.

The $T_{\text {sky }}$ in the atmospheric absorption bands (e.g., $6.3-\mu \mathrm{m}$ water vapor and 9.6- $\mu \mathrm{m}$ ozone absorption band) is higher than that in the atmospheric window bands (i.e., 10 to $12 \mu \mathrm{m}$ ). The $T_{\text {sky }}$ of MLS atmosphere over 10 to $12 \mu \mathrm{m}$ is below $240 \mathrm{~K}$, whereas that of MLW atmosphere can be lower than $170 \mathrm{~K}$. The $T_{\text {sky }}$ in the atmospheric window bands is low due to the high atmospheric transmittance and the low atmospheric absorption.

The relationship between $T_{\text {sky }}$ and PWV under low aerosol loading was better than that of high aerosol loading [Fig. 6(b), Table 3]. It presents an exponential function relationship, which was consistent with previous studies. ${ }^{19}$ The $T_{\text {sky }}$ in the atmospheric window (i.e., SRF 2) mainly ranges from 165 to $290 \mathrm{~K}$, whereas that covering $6.3 \mu \mathrm{m}$ water vapor absorption bands (i.e., SRF 1) ranges from 210 to $290 \mathrm{~K}$. This indicated that a larger dynamic range (i.e., 165 to $290 \mathrm{~K}$ ) is required for $T_{\text {sky }}$ measurements if the thermometers or infrared radiometers operate in atmospheric window bands. In contrast, it is required to cover 170 to $280 \mathrm{~K}$ if the radiometer works in a wider spectral range, which includes water vapor and ozone absorption bands.

In addition, $T_{\text {sky }}$ showed a better exponential relationship with PWV when the instrument was operated in the atmospheric window than that including strong water vapor and ozone

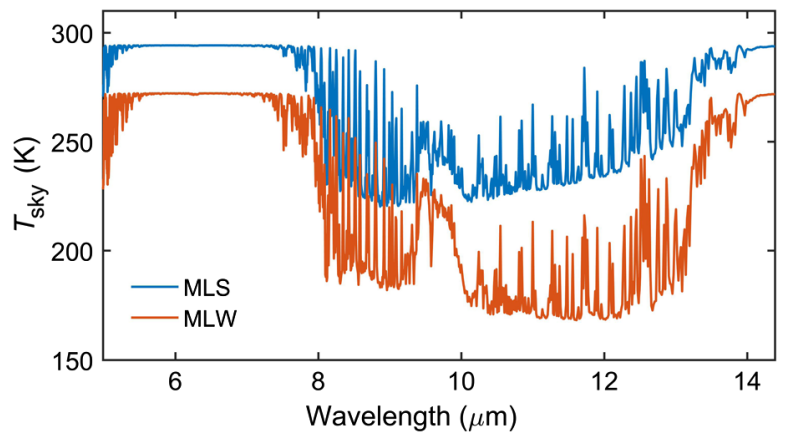

Fig. 5 The $T_{\text {sky }}$ spectrum in 5.0 to $14.5 \mu \mathrm{m}$ of the MLS (blue line) and MLW (red line) atmosphere (aerosol extinction model: urban, VIS $=5 \mathrm{~km}$ ). 

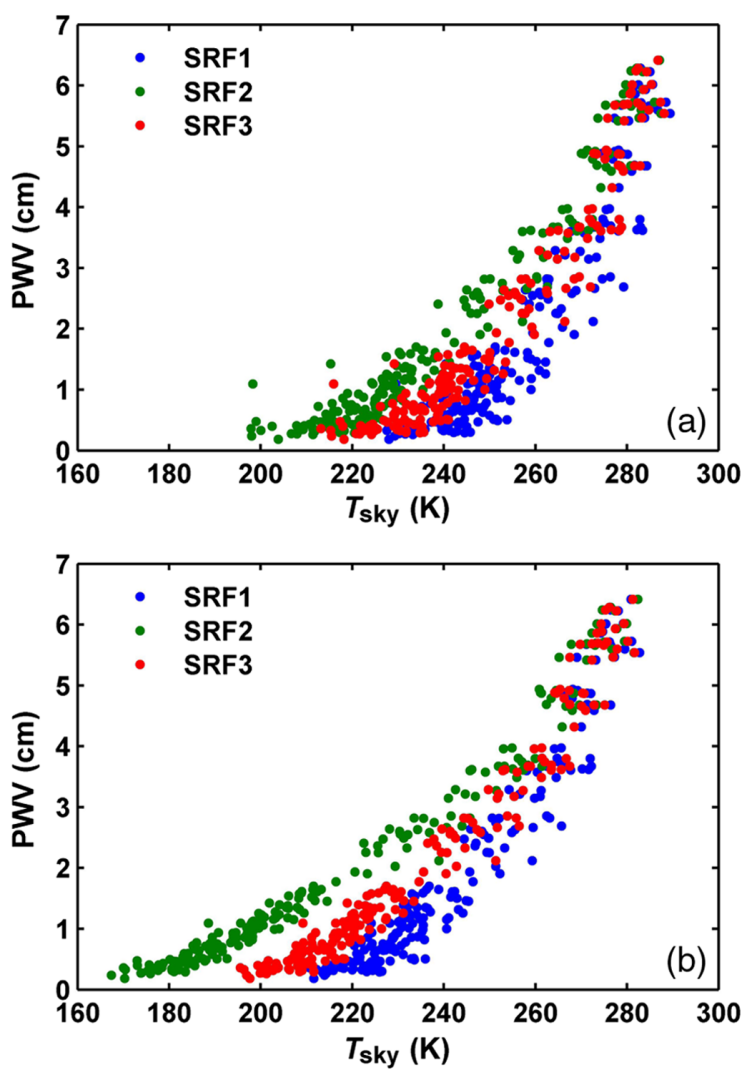

Fig. 6 The scatter plots of the PWV and $T_{\text {sky }}$ for three SRFs. (a) VIS $=1 \mathrm{~km}$ and (b) VIS $=5 \mathrm{~km}$, aerosol model: urban.

absorption bands (Table 3). The $R^{2}$ and RMSE of the retrieved PWV using the exponential function for SRF2 are about 0.971 and $0.310 \mathrm{~cm}$, and that for SRF3 are about 0.960 and $0.362 \mathrm{~cm}$. Furthermore, the relationship between $T_{\text {sky }}$ and PWV in high aerosol loading is worse than that in low aerosol loading (Table 3), suggesting that aerosol loadings have an effect on PWV retrievals. With increasing aerosols, the relationship between $T_{\text {sky }}$ and PWV gradually deteriorates while the simulated $T_{\text {sky }}$ increased [Fig. 6(a)].

The influence of water vapor and temperature change at different pressure level on $T_{\text {sky }}$ change under different response functions were also analyzed. Figure 7 shows the $T_{\text {sky }}$ change for SRFs 1 to 3 due to $5 \%$ and $1 \mathrm{~K}$ increasing in the water vapor mixing ratio and temperature profile at different pressure level for the MLS atmosphere. The SRFs 1 to 3 are sensitive to the atmosphere $>500 \mathrm{hPa}$. The SRF1 was more sensitive to air temperature than SRF2 and SRF3, and SRF1 was more insensitive to water vapor than SRF2 and SRF3. SRF2 is the most sensitive channel to water vapor and the least sensitive channel to temperature for SRFs 1 to 3 . Therefore, it was expected that SRF2 channel can provide more accurate PWV estimation than SRFs 1 and 3. This is consistent with the results of inversion from the simulated data (Tables 2 and 3).

In summary, the ground-based radiometer operated in the atmospheric window could provide PWV with higher accuracy than that including 6.3- and 9.6- $\mu \mathrm{m}$ absorption bands, and it should have the ability to capture the lower $T_{\text {sky }}$ of the atmosphere. In practical applications, the appropriate channel should be selected according to the detection accuracy of PWV and the PWV characteristics of the study area. Considering the results and channel characteristics of the actual infrared thermometers, the following discussions mainly focus on the results of SRFs 2 and 3.

\subsection{Effect of Aerosol on $\mathrm{T}_{\text {sky }}$}

To further investigate the influence of aerosols on $T_{\text {sky }}$, the $T_{\text {sky }}$ in different VIS (1 to $4 \mathrm{~km}$ ) was compared with that for MODTRAN default urban aerosol model (VIS $=5 \mathrm{~km}$ ) (Fig. 8). It can 
Zhou et al.: Sensitivity analyses of precipitable water vapor retrieval...
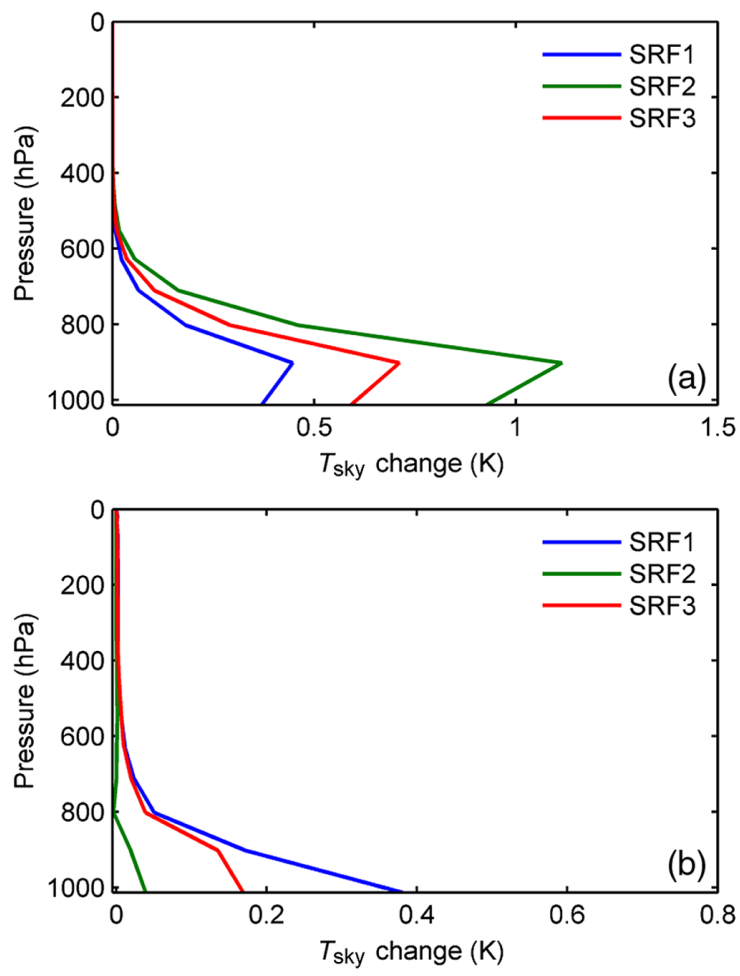

Fig. $7 T_{\text {sky }}$ change for SRFs 1 to 3 due to $5 \%$ and $1 \mathrm{~K}$ increasing in the water vapor mixing ratio (a) and temperature (b) profile at different pressure level for the MLS atmosphere.

Table 2 The fitting results of PWV with $T_{\text {sky }}$ using the exponential function for different SRFs $(\mathrm{VIS}=1 \mathrm{~km})$.

\begin{tabular}{lccc}
\hline \hline SRF & Model & $R^{2}$ & RMSE $(\mathrm{cm})$ \\
\hline SRF1 $(9 \mu \mathrm{m})$ & $y=1.605 e-05 * \exp (0.0499 * x)$ & 0.9177 & 0.5188 \\
SRF2 $(11.5 \mu \mathrm{m})$ & $y=0.001661 * \exp (0.02903 * x)$ & 0.9576 & 0.3726 \\
SRF3 (apogee) & $y=0.000158 * \exp (0.03712 * x)$ & 0.9462 & 0.4194 \\
\hline \hline
\end{tabular}

Table 3 The fitting results of PWV with $T_{\text {sky }}$ using the exponential function for different SRFs $(\mathrm{VIS}=5 \mathrm{~km})$.

\begin{tabular}{lccc}
\hline \hline SRF & Model & $R^{2}$ & RMSE $(\mathrm{cm})$ \\
\hline SRF1 $(9 \mu \mathrm{m})$ & $y=0.0001986 * \exp (0.03708 * x)$ & 0.9425 & 0.4339 \\
SRF2 $(11.5 \mu \mathrm{m})$ & $y=0.01456 * \exp (0.02178 * x)$ & 0.9707 & 0.3096 \\
SRF3 (apogee) & $y=0.001616 * \exp (0.02966 * x)$ & 0.9598 & 0.3617 \\
\hline \hline
\end{tabular}

be seen that atmospheric aerosol loading change have an obvious effect on $T_{\text {sky }} . T_{\text {sky }}$ increased significantly with the aerosol concentration especially for the dry atmospheric conditions (i.e., PWV $<2 \mathrm{~cm}$ ). The influence of aerosol change on $T_{\text {sky }}$ decreases with the increase of water vapor. Furthermore, the effect of aerosol on $T_{\text {sky }}$ is also affected by the SRF. The $T_{\text {sky }}$ corresponding to SRF2 is more affected by aerosol than SRF3. The $T_{\text {sky }}$ difference of SRF2 between VIS $=1 \mathrm{~km}$ and VIS $=5 \mathrm{~km}$ can reach $35 \mathrm{~K}$ when $\mathrm{PWV}<1 \mathrm{~cm}$, whereas that for SRF3 are generally less than $25 \mathrm{~K}$. 

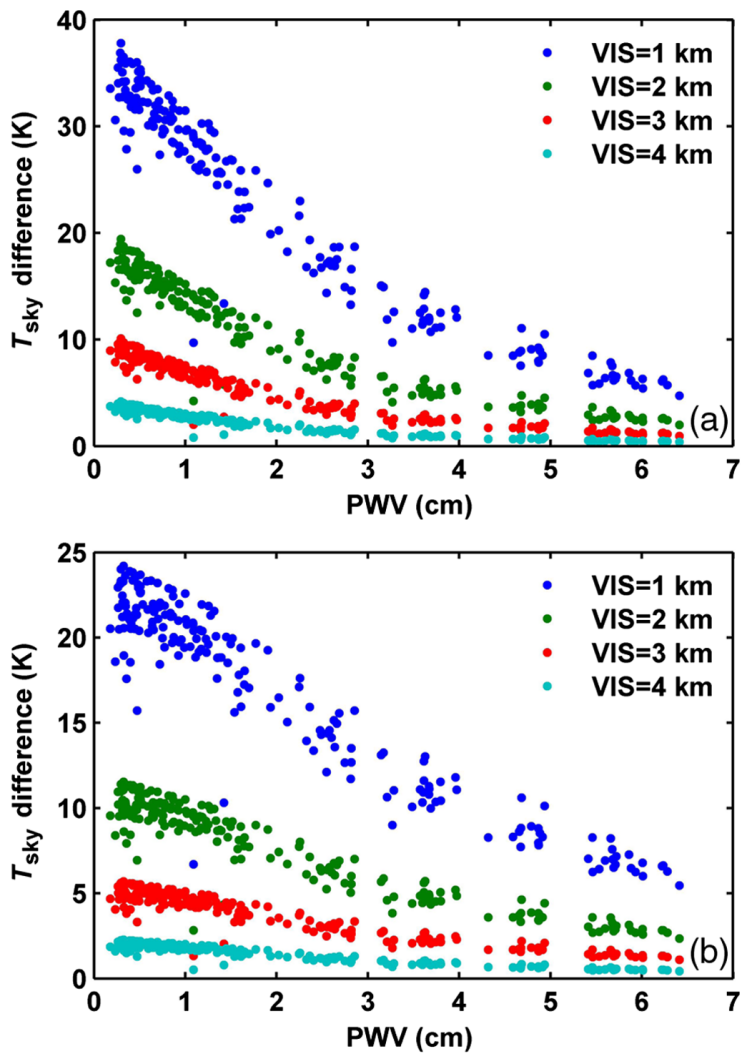

Fig. 8 The $T_{\text {sky }}$ change between different VIS ( 1 to $4 \mathrm{~km}$ ) and MODTRAN default urban aerosol extinction model (VIS $=5 \mathrm{~km}$ ) vary with PWV. (a) SRF2 and (b) SRF3.

Furthermore, the $T_{\text {sky }}$ of MLS and MLW for different VIS (1 to $10 \mathrm{~km}$ ) were also calculated. $T_{\text {sky }}$ increases with VIS, and the $T_{\text {sky }}$ change decreases gradually for large VIS (i.e., $>5 \mathrm{~km}$ ) (Figs. 9 and 10). $T_{\text {sky }}$ change for MLS can reach $18 \mathrm{~K}$ when VIS varies from 1 to $10 \mathrm{~km}$. In comparison, the change of $T_{\text {sky }}$ for MLW can reach $35 \mathrm{~K}$. It indicates that the aerosol effects need to be considered when PWV was directly retrieved from $T_{\text {sky }}$ measurement (i.e., using the exponential function). In comparison, the effect of rural and urban aerosol on $T_{\text {sky }}$ for different VIS is comparable, indicating that the aerosol type has little influence on the PWV retrieval.

In conclusion, aerosols have an important influence on $T_{\text {sky }}$ due to their extinction effect. It is difficult to identify whether $T_{\text {sky }}$ change is caused by aerosol or water vapor change when PWV retrieval was performed directly from $T_{\text {sky }}$. Therefore, it is difficult to obtain high-precision PWV from $T_{\text {sky }}$ measurement alone, especially for the high aerosol loading conditions. It indicates that it is necessary to correct the influence of aerosols in the PWV retrieval from $T_{\text {sky }}$.

\subsection{Effect of $V Z A$ on $\mathrm{T}_{\text {sky }}$}

The influence of VZA on the $T_{\text {sky }}$ was also analyzed. The results showed that $T_{\text {sky }}$ increase with VZA, and $T_{\text {sky }}$ have a good correlation with VZA (Fig. 11). Furthermore, the influence of VZA on $T_{\text {sky }}$ is also affected by the SRF. The $T_{\text {sky }}$ in the atmospheric windows region (i.e., SRF2) is more sensitive to VZA, with the $T_{\text {sky }}$ changes of MLS atmosphere due to the 60 deg change of VZA can reach up to $20 \mathrm{~K}$. In comparison, the $T_{\text {sky }}$ changes of MLW atmosphere due to the 60 deg change of VZA are about $15 \mathrm{~K}$. This indicates that the influence of VZA on $T_{\text {sky }}$ in moist atmospheric conditions is greater than that in dry conditions.

\subsection{Neural Network Model Results}

In this study, half of the simulated datasets were randomly selected to train the $\mathrm{NN}$, and the remaining half were used to evaluate the accuracy of the trained model. As mentioned in 
Zhou et al.: Sensitivity analyses of precipitable water vapor retrieval...
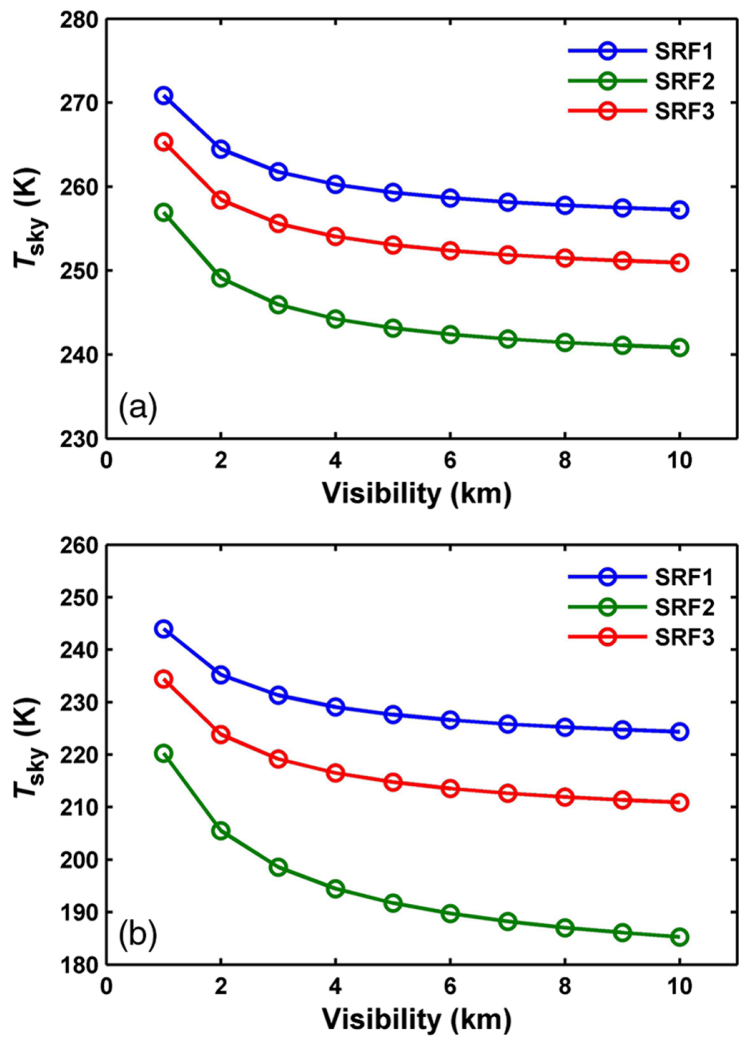

Fig. 9 The relationship between $T_{\text {sky }}$ (rural aerosol model) with VIS for different SRFs. (a) MLS and (b) MLW atmosphere.
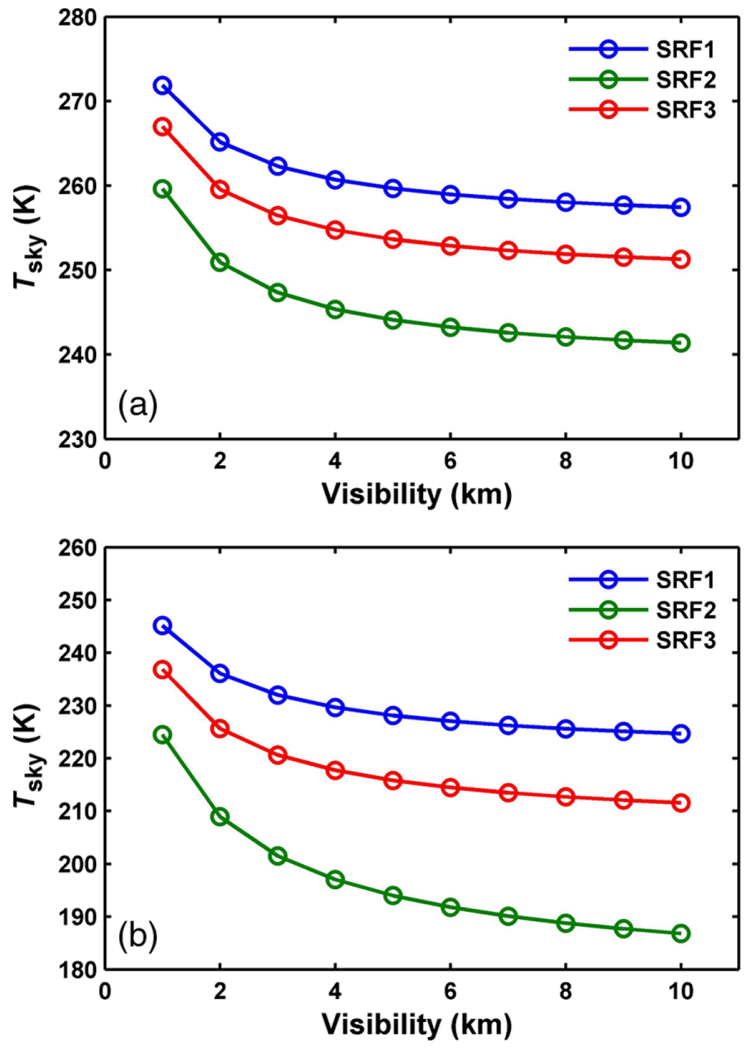

Fig. 10 The relationship between $T_{\text {sky }}$ (urban aerosol model) with VIS for different SRFs. (a) MLS and (b) MLW atmosphere. 

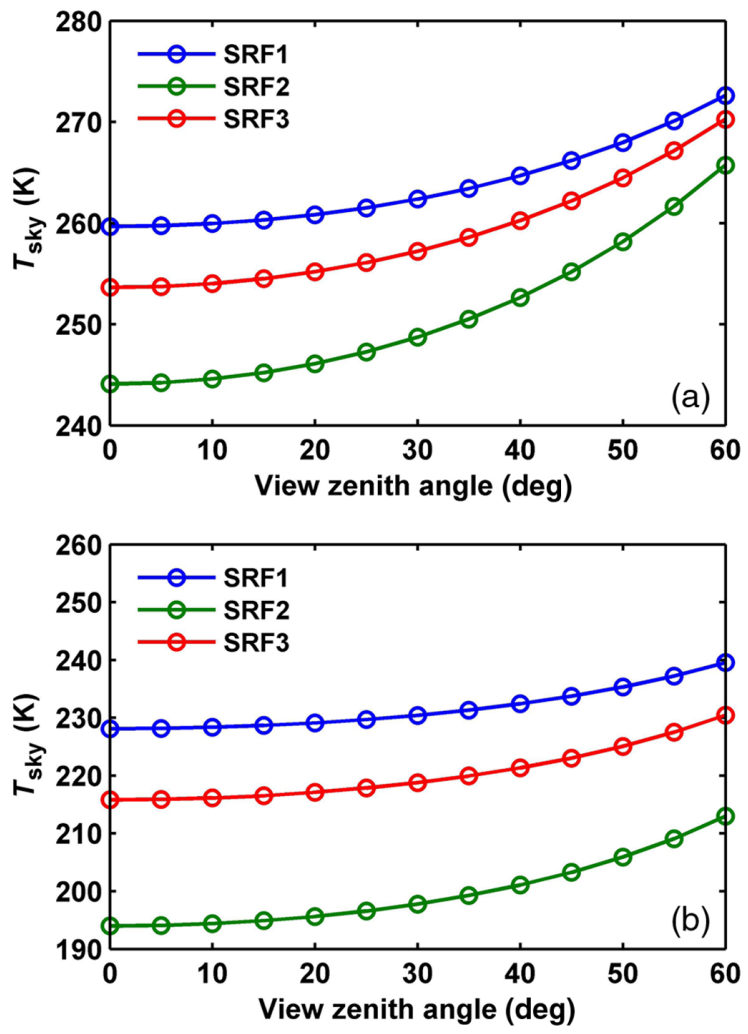

Fig. 11 The relationship between $T_{\text {sky }}$ (urban aerosol model, VIS $=5 \mathrm{~km}$ ) with VZA for different SRFs. (a) MLS and (b) MLW atmosphere.

Sec. $2, T_{\text {sky }}$ is not only affected by the atmospheric humidity profile but also by the atmospheric temperature and other atmospheric composition profiles. According to the temperature lapse rate of atmosphere, it is expected the near-surface air temperature $\left(T_{\text {air }}\right)$ can represent the atmospheric temperature profile to a certain extent.

Furthermore, near-surface $\mathrm{RH}$ and $T_{\text {air }}$ can also be easily obtained at stations. Therefore, $T_{\text {air }}$ and RH were also considered to be used as the inputs for the $\mathrm{NN}$ model. In general, the other absorbing gases profile (e.g., $\mathrm{O}_{3}, \mathrm{CO}_{2}, \mathrm{CH}_{4}$, and $\mathrm{N}_{2} \mathrm{O}$ ) with high accuracy are difficult to obtain, so these gases were not taken into account in this study.

Aerosols have a significant influence on $T_{\text {sky }}$, and the influence of aerosols should be taken into account in the inversion of PWV. However, it is usually difficult to obtain high-precision aerosol information. This study attempts to reduce the impact of aerosols on PWV retrieval using dual-angle $T_{\text {sky }}$ observations (i.e., 0 deg and $30 \mathrm{deg}$ ).

Table 4 shows the PWV retrieval results of the NN model for different inputs. In general, the PWV accuracy of the NN models is better than the exponential fitting model. The accuracy of the NN model was not obviously improved when RH was added to the model, which indicates that

Table 4 Results of NN model based on different factors.

\begin{tabular}{|c|c|c|c|c|c|c|}
\hline \multirow[b]{2}{*}{ Model } & \multicolumn{3}{|c|}{ SRF2 } & \multicolumn{3}{|c|}{ SRF3 (apogee) } \\
\hline & $R^{2}$ & RMSE $(\mathrm{cm})$ & Bias $(\mathrm{cm})$ & $R^{2}$ & RMSE (cm) & Bias $(\mathrm{cm})$ \\
\hline 1. $T_{\text {sky }}(0 \mathrm{deg})$ & 0.945 & 0.440 & 0.006 & 0.945 & 0.439 & 0.002 \\
\hline 2. $T_{\text {sky }}(0 \mathrm{deg}), \mathrm{RH}$ & 0.946 & 0.439 & -0.009 & 0.946 & 0.428 & -0.005 \\
\hline 3. $T_{\text {sky }}(0 \mathrm{deg}), T_{\text {air }}$ & 0.968 & 0.357 & -0.002 & 0.969 & 0.346 & -0.008 \\
\hline 4. $T_{\text {sky }}(0 \mathrm{deg}), T_{\text {sky }}(30 \mathrm{deg}), T_{\text {air }}$ & 0.989 & 0.191 & 0.002 & 0.988 & 0.202 & -0.007 \\
\hline
\end{tabular}



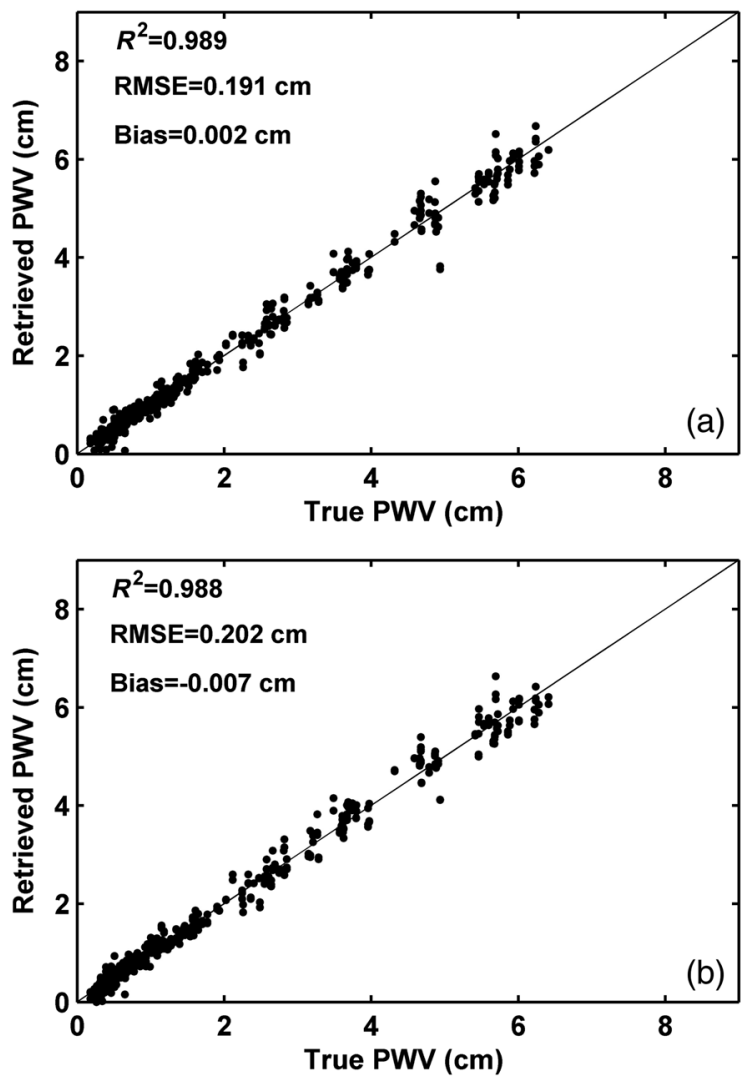

Fig. 12 The scatter plots of the retrieved and true PWV by model 4. (a) SRF2 and (b) SRF3.

the influence of RH on PWV retrieval can be negligible. In contrast, the accuracy of the model is improved when $T_{\text {air }}$ (model 3) was included, with the RMSE decreased from 0.439 to $0.357 \mathrm{~cm}$ for SRF2. It is noteworthy that the accuracy of PWV retrievals is obviously improved when the dual-angle $T_{\text {sky }}$ was used (model 4). The $R^{2}$, RMSE, and bias of model 4 for SRF2 were 0.989 , 0.191 , and $0.002 \mathrm{~cm}$, respectively, and were $0.988,0.202$, and $-0.007 \mathrm{~cm}$ for SRF3 (Fig. 12). It indicates that dual-angle $T_{\text {sky }}$ model can effectively reduce the influence of aerosol on PWV retrievals and conduced greatly to PWV estimation from the ground-based infrared $T_{\text {sky }}$ measurements.

\section{Conclusions}

Sensitivity analyses of PWV retrieval from the ground-based infrared measurements in clear sky conditions were carried out by radiative transfer simulation and retrieval experiments. The effects of SRF (i.e., central wavelength and FWHM), VZA, aerosol loading, and aerosol types on $T_{\text {sky }}$ and PWV retrieval were analyzed. The results showed that the SRF, VZA, and aerosol loading have significant effects on $T_{\text {sky }}$ and PWV retrievals.

In general, $T_{\text {sky }}$ increases with PWV and has an exponential relationship with PWV. Furthermore, $T_{\text {sky }}$ showed a better relationship with PWV when the sensor was operated in the atmospheric window than that including strong water vapor and ozone absorption bands. $T_{\text {sky }}$ increased with the aerosol loading, the fitting relationship between $T_{\text {sky }}$ and PWV will get worse with increasing aerosol loading. In contrast, the influence of aerosol type on $T_{\text {sky }}$ is relatively small.

A PWV retrieval algorithm was proposed by NN approach using $T_{\text {sky }}$ and other ancillary data such as $T_{\text {air }}$ and RH. The results showed that the PWV inversion model based on the single angle $T_{\text {sky }}$ (i.e., $0 \mathrm{deg}$ ) is more susceptible to aerosols. In contrast, the PWV inversion model based on dual-angle $T_{\text {sky }}$ (i.e., 0 deg and $30 \mathrm{deg}$ ) can significantly reduce the effects of aerosols. 
Furthermore, $T_{\text {air }}$ can also effectively improve the accuracy of the PWV retrieval. The RMSE of the PWV retrievals by NN model using dual-angle $T_{\text {sky }}$ and $T_{\text {air }}$ can be less than $0.20 \mathrm{~cm}$.

In summary, the SRF of the radiometer and aerosol have an important effect on $T_{\text {sky }}$ and the accuracy of PWV retrievals. In practical applications, the appropriate channel should be selected according to the accuracy requirements for PWV and the characteristics of PWV over the study area. Aerosol must be considered for the PWV retrieval approach using the single angle $T_{\text {sky }}$, and the aerosol effects can be obviously reduced by the dual-angle $T_{\text {sky }}$ retrieval approach. In the future, field observations by actual infrared radiometer such as apogee SI series infrared radiometer will be carried out to evaluate the performance of the PWV retrieval algorithm.

\section{Acknowledgments}

This work was supported by the National Natural Science Foundation of China (Grant Nos. 41475026 and 41475032) and the China Meteorological Administration Special Public Welfare Research Fund (Grant No. GYHY201406001). The authors would like to thank the Space Science and Engineering Center of University of Wisconsin-Madison for sharing the Clear Sky Global Training Database.

\section{References}

1. M. Bevis et al., "GPS meteorology: remote sensing of atmospheric water vapor using GPS," J. Geophys. Res. Atmos. 97(D14), 15787-15801 (1992).

2. A. E. Dessler, Z. Zhang, and P. Yang, "Water-vapor climate feedback inferred from climate fluctuations, 2003-2008," Geophys. Res. Lett. 35(20), 293-310 (2008).

3. T. L. Smith et al., "Using GPS-IPW in a 4-D data assimilation system," Earth Planets Space 52(11), 921-926 (2000).

4. H. Nakamura, K. Koizumi, and N. Mannoji, "Data assimilation of GPS precipitable water vapor to the JMA mesoscale numerical weather prediction model and its impact on rainfall forecasts," J. Meteorol. Soc. Jpn. 82(1), 441-452 (2004).

5. Z. L. Li et al., "Satellite-derived land surface temperature: current status and perspectives," Remote Sens. Environ. 131(8), 14-37 (2013).

6. Y. Julien et al., "Near-real-time estimation of water vapor column from MSG-SEVIRI thermal infrared bands: implications for land surface temperature retrieval," IEEE Trans. Geosci. Remote Sens. 53(8), 4231-4237 (2015).

7. J. A. Sobrino and M. Romaguera, "Water-vapour retrieval from Meteosat 8/SEVIRI observations," Int. J. Remote Sens. 29(3), 741-754 (2008).

8. K. P. Czajkowski et al., "Thermal remote sensing of near-surface water vapor," Remote Sens. Environ. 79(2-3), 253-265 (2002).

9. K. M. Firsov et al., "Total water vapor content retrieval from sun photometer data," Atmos. Oceanic Opt. 26(4), 281-284 (2013).

10. H. Liu et al., "An improved physical split-window algorithm for precipitable water vapor retrieval exploiting the water vapor channel observations," Remote Sens. Environ. 194, 366-378 (2017).

11. H. Liu et al., "Evaluation of MODIS water vapour products over China using radiosonde data," Int. J. Remote Sens. 36(2), 680-690 (2015).

12. Z. H. Li, J. P. Muller, and P. Cross, "Comparison of precipitable water vapor derived from radiosonde, GPS, and moderate-resolution imaging spectroradiometer measurements," J. Geophys. Res. 108(D20), 4651 (2003).

13. Y. J. Kaufman and B. C. Gao, "Remote sensing of water vapour in the near IR from EOS/MODIS," IEEE Trans. Geosci. Remote Sens. 30(5), 871-884 (1992).

14. J. A. Sobrino, J. E. Kharraz, and Z. L. Li, "Surface temperature and water vapour retrieval from MODIS data," Int. J. Remote Sens. 24(24), 5161-5182 (2003).

15. F. Alshawaf et al., "Accurate estimation of atmospheric water vapor using GNSS observations and surface meteorological data," IEEE Trans. Geosci. Remote Sens. 53(7), 3764-3771 (2015). 
16. M. D. Lebsock et al., "The feasibility of water vapor sounding of the cloudy boundary layer using a differential absorption radar technique," Atmos. Meas. Tech. 8(9), 3631-3645 (2015).

17. R. N. Halthore et al., "Sun photometric measurements of atmospheric water vapor column abundance in the 940-nm band," J. Geophys. Res.: Atmos. 102(D4), 4343-4352 (1997).

18. A. Maghrabi and R. Clay, "Precipitable water vapour estimation on the basis of sky temperatures measured by a single-pixel IR detector and screen temperatures under clear skies," Meteorol. Appl. 17(3), 279-286 (2010).

19. F. M. Mims, III, L. H. Chambers, and D. R. Brooks, "Measuring total column water vapor by pointing an infrared thermometer at the sky," Bull. Am. Meteorol. Soc. 92(10), 1311-1320 (2011).

20. K.-N. Liou, An Introduction to Atmospheric Radiation, 2nd ed., Academic Press, Amsterdam, Boston (2002).

21. E. Borbas et al., "Global profile training database for satellite regression retrievals with estimates of skin temperature and emissivity," in Int. ATOVS Study Conf., pp. 763-770 (2005).

22. Apogee Instruments Inc., "Infrared radiometer owner's Manual," https://www .apogeeinstruments.com/product-manuals/ (accessed 25 October 2019).

23. A. Berk et al., MODTRAN 5.2. 1 User's Manual, Spectral Sciences Inc., Burlington, Massachusetts (2011).

24. R. Richter, "Some aspects of the atmospheric radiance model of LOWTRAN 6," Int. J. Remote Sens. 6(11), 1773-1777 (1985).

25. P. Wang, W. H. Knap, and P. Stammes, "Cloudy sky shortwave radiative closure for a baseline surface radiation network site," J. Geophys. Res.: Atmos. 116(D8), D08202 (2011).

26. F. X. Kneizys et al., Users Guide to LOWTRAN 7, Air Force Geophysics Lab, Hanscom AFB, MA (1988).

27. J. D. Jang, A. A. Viau, and F. Anctil, "Neural network estimation of air temperatures from AVHRR data," Int. J. Remote Sens. 25(21), 4541-4554 (2004).

28. S. Rehman and M. Mohandes, "Artificial neural network estimation of global solar radiation using air temperature and relative humidity," Energy Policy 36(2), 571-576 (2008).

Hailei Liu is an associate professor at Chengdu University of Information Technology (CUIT). He received his BS degree from Henan Agricultural University and his MS degree from CUIT. He received his PhD from the Institute of Atmospheric Physics, Chinese Academy of Sciences. His primary interests are in passive microwave remote sensing, water vapor and land surface properties retrievals, and applications of satellite data.

Biographies of the other authors are not available. 